\title{
Wide Electrocaloric Temperature Range Induced by Ferroelectric to Antiferroelectric Phase Transition
}

\author{
Xiaohui Sun ${ }^{1}$, Houbing Huang ${ }^{2, *} \mathbb{C}$, Hasnain Mehdi Jafri ${ }^{2}$, Junsheng Wang ${ }^{2}$, Yongqiang Wen ${ }^{1}$ \\ and Zhi-Min Dang ${ }^{3, *}$ \\ 1 Department of Chemistry, University of Science and Technology Beijing, Beijing 100083, China; \\ xiaohui_sunbj@163.com (X.S.); wyq_wen@ustb.edu.cn (Y.W.) \\ 2 Advanced Research Institute of Multidisciplinary Science, Beijing Institute of Technology, Beijing 100081, \\ China; shm.fizex@gmail.com (H.M.J.); junsheng.wang@bit.edu.cn (J.W.) \\ 3 State Key Laboratory of Power System and Department of Electrical Engineering, Tsinghua University, \\ Beijing 100084, China \\ * $\quad$ Correspondence: hbhuang@bit.edu.cn (H.H.); dangzm@tsinghua.edu.cn (Z.-M.D.)
}

Received: 29 March 2019; Accepted: 14 April 2019; Published: 23 April 2019

Abstract: The ferroelectric (FE) to antiferroelectric (AFE) phase transition tuning the temperature range of electrocaloric (EC) effects was investigated using phenomenological Landau-Devonshire theory. Contrary to ferroelectric to paraelectric (PE) phase transitions for electrocaloric effects, the ferroelectric to antiferroelectric phase transition was adopted to obtain large entropy changes under an applied electric field in a Sm-doping $\mathrm{BiFeO}_{3}$ system. In addition, the doping composition and hydrostatic pressure was observed to tune the ferroelectricantiferroelectric-paraelectric phase transition temperatures and broaden the operating temperature range of electrocaloric effects. The optimal wide temperature range of $\sim 78 \mathrm{~K}$ was observed at $3 \mathrm{GPa}$ compressive hydrostatic pressures and $0.05 \mathrm{Sm}$-doping $\mathrm{BiFeO}_{3}$. The present study paves the way to designing high efficiency cooling devices with larger operating temperature spans.

Keywords: electrocaloric effect; thermodynamic calculation; ferroelectric-antiferroelectric phase transition; wide temperature range

\section{Introduction}

The electrocaloric (EC) effect has attracted great attention due to its potential to replace current domestic and industrial refrigeration systems to those based on solid-state cooling technology [1-9]. Usually, large EC effects in ceramics are reported within a narrow temperature range, sometimes even at a fixed temperature around the temperature of the ferroelectric (FE)-paraelectric (PE) phase transition above room temperature, which limits its applications. A wide operational temperature range near room temperature is highly desired in order to develop high performance EC cooling devices [10-18]. For instance, $\mathrm{Sn}^{4+}$ doping was reported to increase the operating temperature range of the EC effect in $\mathrm{Ba}_{0.9} \mathrm{Sr}_{0.1}\left(\mathrm{Ti}_{0.9} \mathrm{Zr}_{0.1}\right)_{0.95} \mathrm{Sn}_{0.05} \mathrm{O}_{3}$ ceramics to $20 \mathrm{~K}$ [13]. The modified $\mathrm{Ba}\left(\mathrm{Zr}_{\mathrm{x}} \mathrm{Ti}_{1-\mathrm{x}}\right) \mathrm{O}_{3}$ ceramic generated a wide $\mathrm{EC}$ temperature change range at about $30 \mathrm{~K} \mathrm{[16]} \mathrm{and} 50 \mathrm{~K}$ in Y-substituted $\mathrm{BaTiO}_{3}$ ceramics [19]; even a temperature span from room temperature to $140{ }^{\circ} \mathrm{C}\left(\sim 115^{\circ} \mathrm{C}\right.$ range $)$ in $\mathrm{BaTiO}_{3}$ ceramics by rare-earth substitution was obtained [14]. According the results reported earlier, doping can vary the temperature range of different materials. Additionally, it has been demonstrated that the compressive or tensile strain induced by external stimuli (electric field, stress, pressure) can also remarkably change the spontaneous polarization of ferroelectrics, which influences the transition temperature range of the EC effect further [20-23].

Previous studies, in order to acquire a large adiabatic temperature change, mainly focused on the transition from the FE phase to the PE phase [24-27]. Later, the EC effect of the electric field-induced 
antiferroelectric (AFE) phase was proposed $[15,28,29]$. Lou et al. [30] reported that the phase transition from the AFE to the FE phase led to a giant EC effect in $\mathrm{PbZrO}_{3}$ thin films. Wang et al. [31] reported a large positive EC effect in a broad temperature range $(\sim 110 \mathrm{~K})$ in $\mathrm{Pb}_{0.97} \mathrm{La}_{0.02}\left(\mathrm{Zr}_{0.65} \mathrm{Sn}_{0.3} \mathrm{Ti}_{0.05}\right) \mathrm{O}_{3}$ (PLZST) relaxor AFE thin films. Zhao et al. [11] reported the coexistence of giant negative and positive EC effects in $\mathrm{Na}_{0.5} \mathrm{Bi}_{4.5} \mathrm{Ti}_{4} \mathrm{O}_{15}$ (NBT) ferroelectric films over a broad temperature range. Surprisingly, the EC effect in NBT-based samples is caused by the FEAFE phase transition, which is different from previous FEPE and AFEFE phase transitions. The existence of the FEAFE phase transition in Sm-doping $\mathrm{BiFeO}_{3}$ (BFO) systems have been reported [32-34], however, the EC effect of the phase transition from FE to AFE in Sm-doping BFO ceramics has never been explored. BFO has a high leakage of current due to the existence of oxygen vacancies or defects, while a reduction in leakage current was observed with increases in Sm composition [35,36]. The breakdown of the electric field can be increased in Sm-doping $\mathrm{BFO}$, hence the high entropy change also can be enhanced by chemical element doping. In this work, the existence of a giant electrocaloric response over a broad temperature range in the Sm-doping BFO system was investigated. The entropy change of different $\mathrm{Sm}$-doping composition and hydrostatic pressure was calculated and discussed.

\section{Theoretical Description}

The theoretical model of describing an AFE phase is a simple two-sublattice model by Kittel [37]. Cross and Okada developed a phenomenological model using Gibbs free energy as a function of two dependent FE and AFE order parameters [38,39]. Xue et al. proposed a three-dimensional phenomenological model to successfully describe the temperature-, pressure-, and composition-induced ferroelectric to antiferroelectric phase transitions, which are consistent with the experimental phase diagrams [32]. Therefore, we adopted the same model and parameters to investigate the electrocaloric effects of Sm-doping BFO. To distinguish the FE and AFE phases, AFE and FE phases were divided into two sublattices, $a$ and $b$, associated with polarization $\vec{P}_{a}$ and $\vec{P}_{b}$ respectively. If $\vec{P}_{a}$ and $\vec{P}_{b}$ are parallel to each other, the system exhibits the FE phase, as sketched in Figure 1a, otherwise, if $\vec{P}_{a}$ and $\vec{P}_{b}$ are antiparallel, it exhibits the AFE phase, as illustrated in Figure 1b. When $\vec{P}_{a}$ and $\vec{P}_{b}$ are both zero, it exhibits the PE phase.
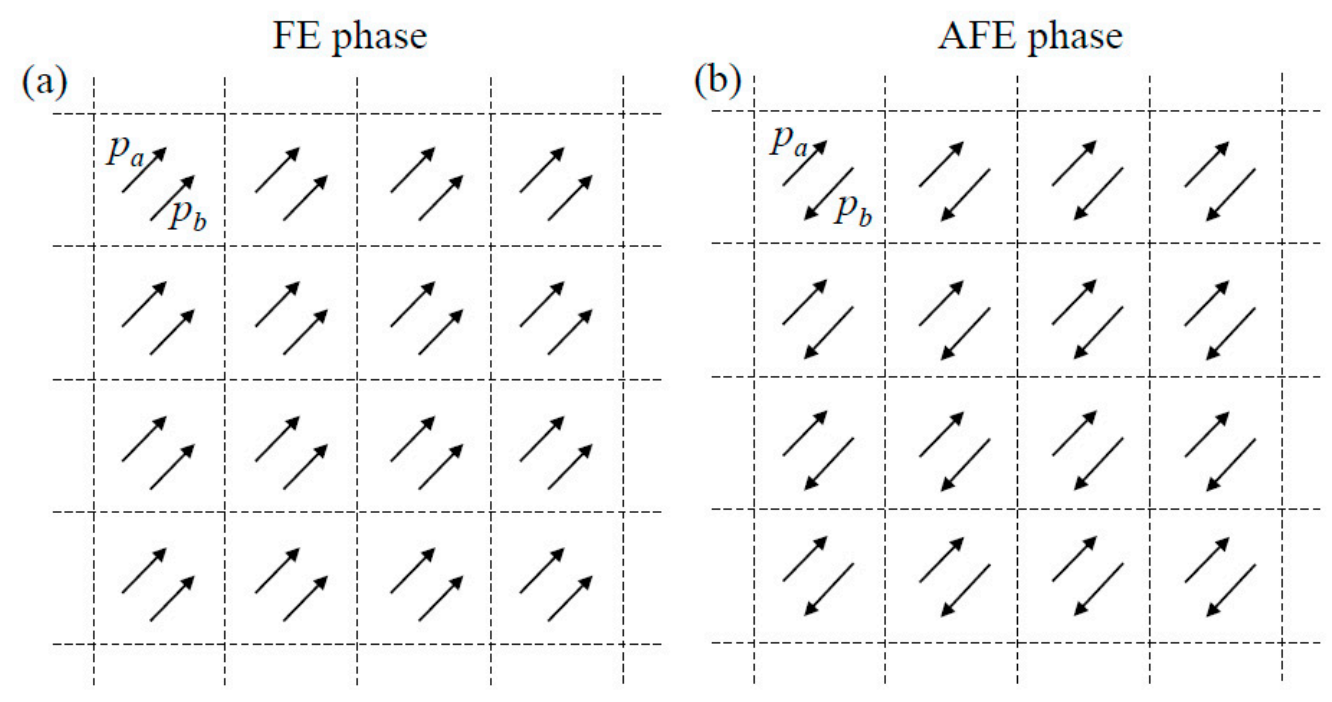

Figure 1. Schematic of the (a) ferroelectric (FE) and (b) antiferroelectric (AFE) phases.

The FE and AFE order parameters, $\vec{p}$ and $\vec{q}$, are defined as follows [40]:

$$
\vec{p}=\frac{1}{2}\left(\overrightarrow{P_{a}}+\overrightarrow{P_{b}}\right), \vec{q}=\frac{1}{2}\left(\vec{P}_{a}^{\prime}-\vec{P}_{b}^{\prime}\right)
$$


In Equation (1), $\vec{P}_{a}^{\prime}$ and $\vec{P}_{b}^{\prime}$ were used instead of $\vec{P}_{a}$ and $\vec{P}_{b}$ to represent the AFE order parameter, because the polarization associated with sublattices of the AFE phase are sometimes different from that of the FE phase.

Taking the unpolarized and unstressed PE phase as the reference state, the total free energy density of the Sm-doping BFO system under an electric field can be expressed as [32]:

$$
\begin{aligned}
f_{\text {total }}=a_{i j} p_{i} p_{j}+ & a_{i j k l} p_{i} p_{j} p_{k} p_{l}+a_{i j k l m n} p_{i} p_{j} p_{k} p_{l} p_{m} p_{n}+b_{i j} q_{i} q_{j}+b_{i j k l} q_{i} q_{j} q_{k} q_{l} \\
& +b_{i j k l m n} q_{i} q_{j} q_{k} q_{l} q_{m} q_{n}+t_{i j k l} p_{i} p_{j} q_{k} q_{l}+\frac{1}{2} s_{i j k l} \sigma_{i j} \sigma_{k l}-Q_{i j k l} p_{i} p_{j} \sigma_{k l} \\
& -\Lambda_{i j k l} q_{i} q_{j} \sigma_{k l}-\frac{1}{2} \varepsilon_{0} E_{i}^{2}-p_{i} E_{i}
\end{aligned}
$$

where $p_{i}$ and $q_{i}$ are the $i$ th components of the FE and AFE order parameters; $a_{i j}, a_{i j k l}, a_{i j k l m n}$ and $b_{i j}, b_{i j k l}, b_{i j k l m n}$ are the FE and AFE dielectric stiffnesses, respectively. $t_{i j k l}$ are coupling coefficients between the FE and AFE order parameters. $s_{i j k l}$ are the elastic compliance constants; $Q_{i j k l}$ and $\Lambda_{i j k l}$ are corresponding electrostrictive coefficients; $\boldsymbol{\sigma}$ is $i$ th component of applied stress in Voigt notation; $\varepsilon_{0}$ is the vacuum permittivity; $E_{i}$ is the external applied electric field. Among all the coefficients, only $a_{11}$ and $b_{11}$ are assumed to be dependent on composition and temperature. All the coefficients used in this work are taken from reference [32].

The applied hydrostatic pressure tensors satisfy $\sigma_{1}=\sigma_{2}=\sigma_{3}=-\sigma$ and $\sigma_{4}=\sigma_{5}=\sigma_{6}=0$. The EC effect was investigated based on indirect measurements using the Maxwell relation $(\partial P / \partial T)_{E}=$ $(\partial S / \partial E)_{T}$, where the total polarization $P$ includes $p_{i}$ and $q_{i}$. It is suggested that the reversible adiabatic change in entropy $(\Delta S)$ can be calculated using the following relations [41]:

$$
\Delta S=-\frac{1}{\rho} \int_{E_{a}}^{E_{b}}\left(\frac{\partial P}{\partial T}\right)_{E} d E
$$

where $E_{a}$ and $E_{b}$ are the initial and final applied electric fields, respectively. $\rho$ is the density of BFO ceramics.

\section{Results and Discussion}

The total polarization (sum of the FE phase and AFE phase) as a function of temperature was calculated for different Sm compositions, shown in Figure 2a. It can be seen that the polarization of pure BFO indicates a first-order phase transition at $1100 \mathrm{~K}$. As the composition of Sm in the BFO system increases, AFE phases are gradually observed. Meanwhile, the transition temperature decreases significantly with increasing Sm composition. As the Sm composition increases above $0.15 \mathrm{Sm}-\mathrm{BFO}$, all the FE phase transforms to AFE phase. Similarly, hydrostatic pressure also can induce the AFE phase and decrease the transition temperature, as shown in Figure $2 \mathrm{~b}$. The temperature range of the FE phase decreases with hydrostatic pressure, and the FE phase disappears at a hydrostatic pressure higher than $5 \mathrm{GPa}$.
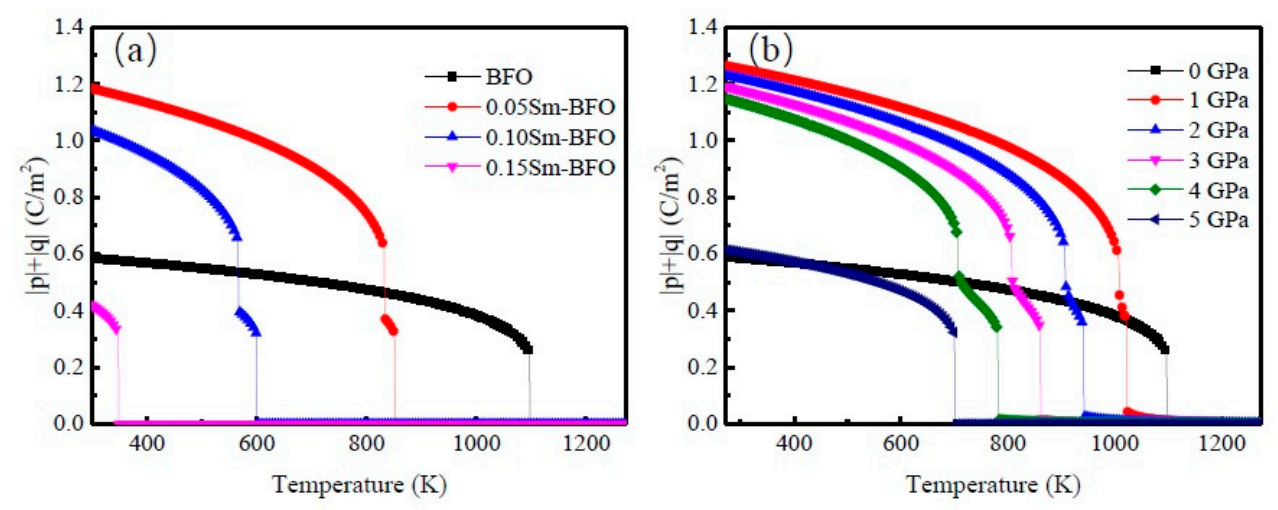

Figure 2. The total polarization with (a) Sm compositions and (b) hydrostatic pressures as a function of temperature. 
First, the temperature span of the EC effect at different $\mathrm{Sm}$ compositions was studied. The entropy changes of the EC effect in $0.05 \mathrm{Sm}-\mathrm{BFO}$ and $0.10 \mathrm{Sm}-\mathrm{BFO}$ were investigated, as shown in Figure 3. Figure 3 a shows the entropy change as a function of temperature with different electric fields including $10,20,30$ and $40 \mathrm{kV} / \mathrm{cm}$. At $10 \mathrm{kV} / \mathrm{cm}$, the entropy change has two peaks at $834 \mathrm{~K}$ and $853 \mathrm{~K}$, which results from FE to AFE, and AFE to PE phase transitions, respectively. In addition, the entropy change also increases with the electric field. The large entropy changes $\Delta S$ of $\sim 5 \mathrm{~J} /(\mathrm{kg} \cdot \mathrm{K})$ and $\sim 4 \mathrm{~J} /(\mathrm{kg} \cdot \mathrm{K})$ were obtained in $0.05 \mathrm{Sm}-\mathrm{BFO}$ and $0.10 \mathrm{Sm}-\mathrm{BFO}$ at an electric field of $40 \mathrm{kV} / \mathrm{cm}$. Remarkably, compared to previous works, we observed a large EC strength $(|\Delta S| /|\Delta E|)$ in Sm-BFO. For example, $\mathrm{BaTiO}_{3}$ thick films exhibited a giant EC effect of $\Delta S=10.1 \mathrm{~J} /(\mathrm{kg} \cdot \mathrm{K})$ at $800 \mathrm{kV} / \mathrm{cm}$ [42]. Therefore, the maximum EC strength in Sm-BFO can be obtained at $0.29 \mathrm{~J} \cdot \mathrm{cm} /(\mathrm{kg} \cdot \mathrm{K} \cdot \mathrm{kV})$, which is one order of magnitude larger than $\mathrm{BaTiO}_{3}$ thick films $(0.013 \mathrm{~J} \cdot \mathrm{cm} /(\mathrm{kg} \cdot \mathrm{K} \cdot \mathrm{kV}))$. Furthermore, the temperature range of the entropy change in $0.10 \mathrm{Sm}-\mathrm{BFO}(\sim 31 \mathrm{~K})$ is wider than that in $0.05 \mathrm{Sm}-\mathrm{BFO}(\sim 18 \mathrm{~K})$, indicating that Sm-doping can broaden the temperature range of the EC effect.
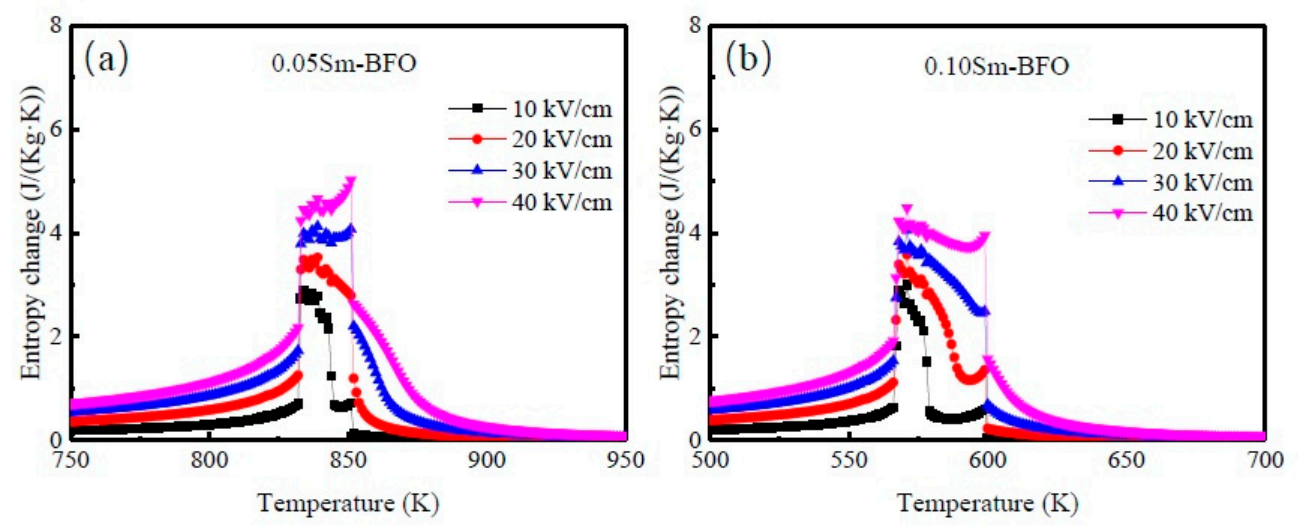

Figure 3. Entropy changes of (a) $0.05 \mathrm{Sm}-\mathrm{BFO}\left(\mathrm{BiFeO}_{3}\right)$ and $(\mathbf{b}) 0.10 \mathrm{Sm}-\mathrm{BFO}$ as a function of temperature under different electric fields of $10,20,30$, and $40 \mathrm{kV} / \mathrm{cm}$.

In addition, the entropy changes of BFO as a function of temperature, at $0 \mathrm{GPa}$ and $3 \mathrm{GPa}$, are shown in Figure 4. As shown in Figure 4a, the value of the entropy change increases with the increasing of the electric field, while only one peak of entropy change can be observed because only FEPE phase transition occurs. However, at $3 \mathrm{GPa}$ hydrostatic pressure on pure BFO, there are two peaks of entropy change (Figure $4 \mathrm{~b}$ ). Since hydrostatic pressure can cause the appearance of the AFE phase, the FEAFEPE phase transition can broaden the temperature range of the EC effect. The AFE phase can be increased by increasing the hydrostatic pressure, and the temperature range ( $\sim 64 \mathrm{~K})$ becomes wider than that ( 44 K) observed at 0 GPa hydrostatic pressure.
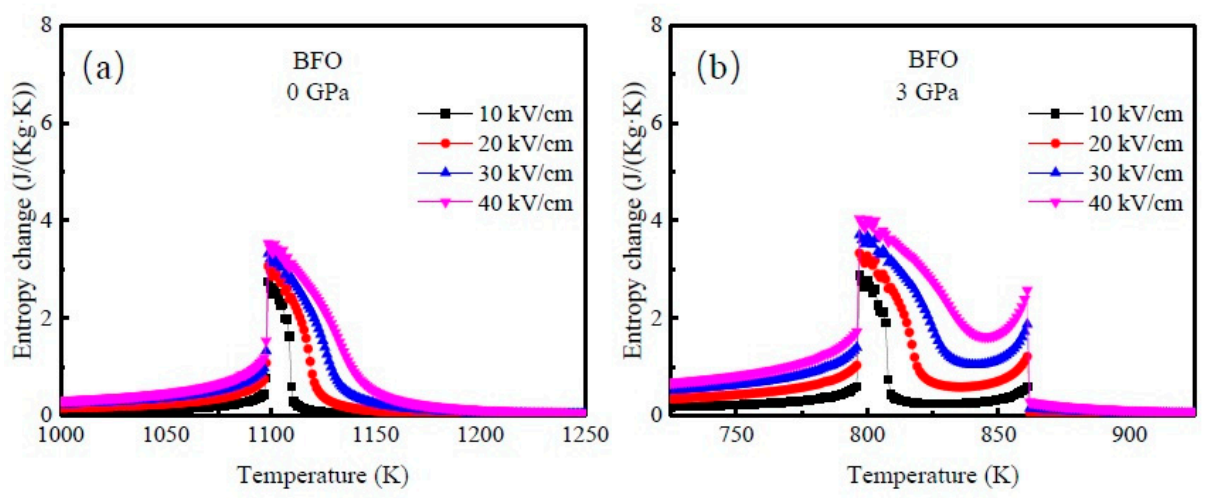

Figure 4. Entropy changes of BFO with different electric fields as a function of temperature under (a) 0 GPa and (b) 3 GPa. 
According to the above results, the Sm doping composition and hydrostatic pressure have a strong influence on the EC effect on temperature range and transition temperature. Therefore, we continued investigate the Sm doping composition and hydrostatic pressure to gain a broad temperature range under an ultralow electric field in Figure 5. As shown in Figure 5a, there are two peaks of entropy change, and the value of the entropy change increases with an increasing of the electric field. The transition temperature range of $0.05 \mathrm{Sm}-\mathrm{BFO}$ can be broadened by applying $3 \mathrm{GPa}$ of hydrostatic pressure. The temperature range of $0.05 \mathrm{Sm}-\mathrm{BFO}$ at $3 \mathrm{GPa}$ is about $78 \mathrm{~K}$, which is wider than that at zero hydrostatic pressure ( $18 \mathrm{~K})$, as shown in Figure 3a. Similarly, the two peaks in entropy changes of $0.10 \mathrm{Sm}-\mathrm{BFO}$ at $0.5 \mathrm{GPa}$ indicate that FEAFEPE phase transitions occurred (Figure $5 \mathrm{~b}$ ). The temperature range of $0.01 \mathrm{Sm}-\mathrm{BFO}$ at $0.5 \mathrm{GPa}(\sim 42 \mathrm{~K})$ is also wider than that at zero hydrostatic pressure $(\sim 31 \mathrm{~K})$, as shown in Figure 3b. Meanwhile, the transition temperature range of $0.10 \mathrm{Sm}-\mathrm{BFO}$ at $0.5 \mathrm{GPa}$ can be broadened by choosing an optimal chemical doping and hydrostatic pressure.
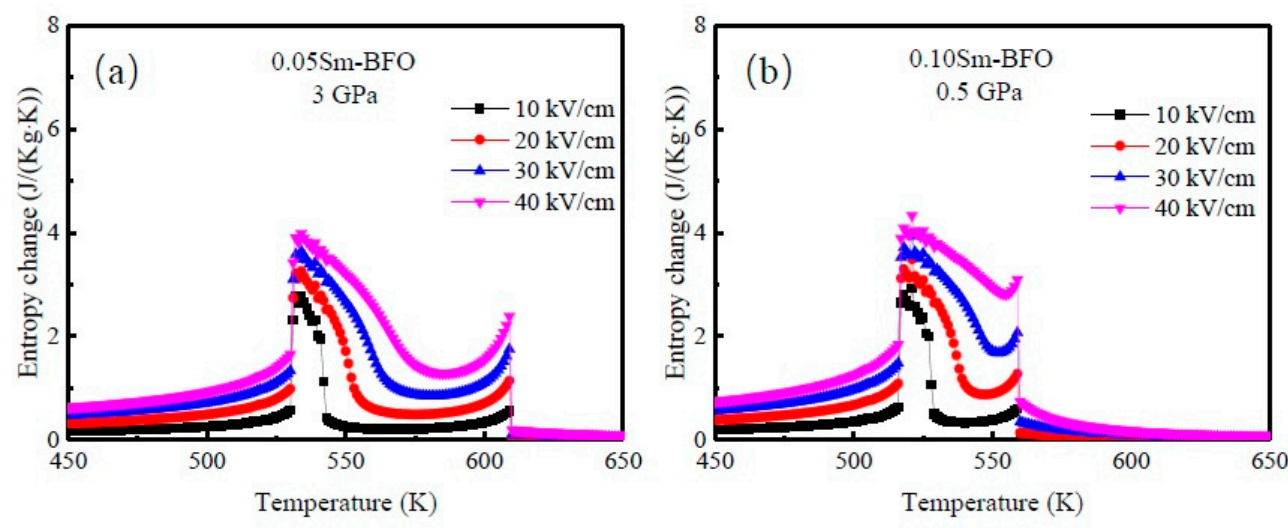

Figure 5. Entropy changes of (a) $0.05 \mathrm{Sm}-\mathrm{BFO}$ with different electric fields as a function of temperature under $3 \mathrm{GPa}$ and (b) $0.10 \mathrm{Sm}-\mathrm{BFO}$ with different electric fields as a function of temperature under $0.5 \mathrm{GPa}$.

\section{Conclusions}

In summary, the ferroelectric to antiferroelectric phase transition tuning of the temperature range of electrocaloric effects was investigated using the phenomenological LandauDevonshire theory. The results show that both the doping composition and hydrostatic pressure can induce the AFE phase. A large entropy change during the FEAFEPE phase transition process can be obtained at $40 \mathrm{kV} / \mathrm{cm}$. Meanwhile, hydrostatic pressure and Sm-doping can broaden the operating temperature range and adjust the ferroelectricantiferroelectricparaelectric phase transition temperature to room temperature, which paves the way in designing high efficiency cooling devices near room temperature.

Author Contributions: X.S. and H.H. carried out the concepts, design, definition of intellectual content, literature search, data acquisition, data analysis and manuscript preparation. H.M.J. carried out manuscript editing. J.W., Y.W. and Z.-M.D. performed manuscript review. All authors have read and approved the content of the manuscript.

Funding: This research was funded by [the National Natural Science Foundation of China] grant number [11504020].

Acknowledgments: This work was sponsored by the National Natural Science Foundation of China (11504020). The authors are grateful to the discussion with Fei Xue, who worked on the phase field model in Pennsylvania State University.

Conflicts of Interest: The authors declare no conflict of interest.

\section{References}

1. Zhang, G.; Li, Q.; Gu, H.; Jiang, S.; Han, K.; Gadinski, M.R.; Haque, M.A.; Zhang, Q.; Wang, Q. Ferroelectric polymer nanocomposites for room-temperature electrocaloric refrigeration. Adv. Mater. 2015, 27, 1450-1454. [CrossRef] 
2. Guo, L.S.; Zhang, Q.M. Electrocaloric Materials for Solid-State Refrigeration. Adv. Mater. 2009, 21, $1983-1987$.

3. Quintero, M.; Ghivelder, L.; Gomez-Marlasca, F.; Parisi, F. Decoupling electrocaloric effect from Joule heating in a solid state cooling device. Appl. Phys. Lett. 2011, 99, 232908. [CrossRef]

4. Chukka, R.; Cheah, J.; Chen, Z.; Yang, P.; Shannigrahi, S.; Wang, J.; Chen, L. Enhanced cooling capacities of ferroelectric materials at morphotropic phase boundaries. Appl. Phys. Lett. 2011, 98, 242902. [CrossRef]

5. Karmanenko, S.F.; Pakhomov, O.V.; Prudan, A.M.; Starkov, A.S.; Eskov, A. Layered ceramic structure based on the electrocaloric elements working as a solid state cooling line. J. Eur. Ceram. Soc. 2007, 27, 3109-3112. [CrossRef]

6. Ožbolt, M.; Kitanovski, A.; Tušek, J.; Poredoš, A. Electrocaloric refrigeration: Thermodynamics, state of the art and future perspectives. Int. J. Refrig. 2014, 40, 174-188. [CrossRef]

7. Correia, T.M.; Kar-Narayan, S.; Young, J.S.; Scott, J.F.; Mathur, N.D.; Whatmore, R.W.; Zhang, Q. PST thin films for electrocaloric coolers. J. Phys. D Appl. Phys. 2011, 44, 165407. [CrossRef]

8. Lu, S.G.; Rožič, B.; Zhang, Q.M.; Kutnjak, Z.; Pirc, R.; Lin, M.; YLi, X.; Lee, G. Comparison of directly and indirectly measured electrocaloric effect in relaxor ferroelectric polymers. Appl. Phys. Lett. 2010, 97, 202901. [CrossRef]

9. Khodayari, A.; Mohammadi, S. Solid-State Cooling Line Based on the Electrocaloric Effect. IEEE Trans. Ultrason. Ferroelectr. Freq. Control 2011, 58, 503-508. [CrossRef]

10. Li, Q.; Zhang, G.; Zhang, X.; Jiang, S.; Zeng, Y.; Wang, Q. Relaxor ferroelectric-based electrocaloric polymer nanocomposites with a broad operating temperature range and high cooling energy. Adv. Mater. 2015, 27, 2236-2241. [CrossRef] [PubMed]

11. Chen, J.; Tang, Z.; Zhao, S. Giant Negative and Positive Electrocaloric Effects Coexisting in Lead-Free $\mathrm{Na}_{0.5} \mathrm{Bi}_{4.5} \mathrm{Ti}_{4} \mathrm{O}_{15}$ Films Over a Broad Temperature Range. Phys. Status. Solidi RRL 2018, 12, 1700443. [CrossRef]

12. Chen, J.; Tang, Z.; Lu, Q.; Zhao, S. Giant negative electrocaloric effect over a broad temperature range in lead-free based $\mathrm{Bi}_{0.5}\left(\mathrm{~K}_{0.15} \mathrm{Na}_{0.85}\right)_{0.05} \mathrm{TiO}_{3}$ relaxor ferroelectric films. J. Alloy. Compd. 2018, 756, 62-67. [CrossRef]

13. Li, T.; Liu, X.; Shi, S.; Yin, Y.; Li, H.; Wang, Q.; Zhang, Y.; Bian, J.; Rajput, S.S.; Long, C.; et al. Large electrocaloric efficiency over a broad temperature span in lead-free $\mathrm{BaTiO}_{3}$-based ceramics near room temperature. Appl. Phys. Lett. 2017, 111, 202902. [CrossRef]

14. Han, F.; Bai, Y.; Qiao, L.J.; Guo, D. A systematic modification of the large electrocaloric effect within a broad temperature range in rare-earth doped $\mathrm{BaTiO}_{3}$ ceramics. J. Mater. Chem. C 2016, 4, 1842-1849. [CrossRef]

15. Geng, W.P.; Liu, Y.; Meng, X.J.; Bellaiche, L.; Scott, J.F.; Dkhil, B.; Jiang, A. Giant Negative Electrocaloric Effect in Antiferroelectric La-Doped $\mathrm{Pb}(\mathrm{ZrTi}) \mathrm{O}_{3}$ Thin Films Near Room Temperature. Adv. Mater. 2015, 27, 3165-3169. [CrossRef] [PubMed]

16. Qian, X.; Ye, H.; Zhang, Y.; Gu, H.; Li, X.; Randall, C.A.; Zhang, Q.M. Giant Electrocaloric Response Over A Broad Temperature Range in Modified $\mathrm{BaTiO}_{3}$ Ceramics. Adv. Funct. Mater. 2014, 24, 1300-1305. [CrossRef]

17. Cao, W.P.; Li, W.L.; Dai, X.F.; Zhang, T.D.; Sheng, J.; Hou, Y.F.; Fei, W.D. Large electrocaloric response and high energy-storage properties over a broad temperature range in lead-free NBT-ST ceramics. J. Eur. Ceram. Soc. 2016, 36, 593-600. [CrossRef]

18. Sun, X.; Huang, H.; Ma, X.; Wen, Y.; Dang, Z.M. Tunable Temperature Range of Stress-Enhanced Electrocaloric Effects in Composition Gradient Bilayers. J. Ceram. Sci. Technol. 2018, 9, 201-208.

19. Zhao, Y.; Liu, X.Q.; Wu, J.W.; Wu, S.Y.; Chen, X.M. Electrocaloric effect in relaxor ferroelectric $\mathrm{Ba}\left(\mathrm{Ti}_{1-\mathrm{x}} \mathrm{Y}_{\mathrm{x}}\right) \mathrm{O}_{3-\mathrm{x} / 2}$ ceramics over a broad temperature range. J. Alloy. Compd. 2017, 729, 57-63. [CrossRef]

20. Zhang, X.; Wang, J.B.; Li, B.; Zhong, X.L.; Lou, X.J.; Zhou, Y.C. Sizable electrocaloric effect in a wide temperature range tuned by tensile misfit strain in $\mathrm{BaTiO}_{3}$ thin films. J. Appl. Phys. 2011, 109, 126102. [CrossRef]

21. Zhang, J.X.; Li, Y.L.; Wang, Y.; Liu, Z.K.; Chen, L.Q.; Chu, Y.H.; Zavaliche, F.; Ramesh, R. Effect of substrate-induced strains on the spontaneous polarization of epitaxial $\mathrm{BiFeO}_{3}$ thin films. J. Appl. Phys. 2007, 101, 114105. [CrossRef]

22. Sun, X.; Huang, H.; Wang, J.; Wen, Y.; Dang, Z.-M. Strain-induced broadening temperature range of electrocaloric effects in ferroelectric superlattices. J. Alloy. Compd. 2019, 777, 821-827. [CrossRef]

23. Huang, H.; Zhang, G.; Ma, X.; Liang, D.; Wang, J.; Liu, Y.; Wang, Q.; Chen, L.-Q. Size effects of electrocaloric cooling in ferroelectric nanowires. J. Am. Ceram. Soc. 2018, 101, 1566-1575. [CrossRef]

24. Zhang, G.; Zhang, X.; Huang, H.; Wang, J.; Li, Q.; Chen, L.Q.; Wang, Q. Toward Wearable Cooling Devices: Highly Flexible Electrocaloric $\mathrm{Ba}_{0.67} \mathrm{Sr}_{0.33} \mathrm{TiO}_{3}$ Nanowire Arrays. Adv. Mater. 2016, 28, 4811-4816. [CrossRef] [PubMed] 
25. Mischenko, A.S.; Zhang, Q.; Scott, J.F.; Whatmore, R.W.; Mathur, N.D. Giant electrocaloric effect in thin-film $\mathrm{PbZr}_{0.95} \mathrm{Ti}_{0.05} \mathrm{O}_{3}$. Science 2006, 311, 1270-1271.

26. Neese, B.; Chu, B.J.; Lu, S.G.; Wang, Y.; Furman, E.; Zhang, Q.M. Large Electrocaloric Effect in Ferroelectric Polymers Near Room Temperature. Science 2008, 321, 821-823. [CrossRef]

27. Saranya, D.; Chaudhuri, A.R.; Parui, J.; Krupanidhi, S.B. Electrocaloric effect of PMN-PT thin films near morphotropic phase boundary. Bull. Mater. Sci. 2009, 32, 259-262. [CrossRef]

28. Zheng, G.P.; Uddin, S.; Zheng, X.C.; Yang, J.H. Structural and electrocaloric properties of multiferroic-BiFeO 3 doped $0.94 \mathrm{Bi}_{0.5} \mathrm{Na}_{0.5} \mathrm{TiO}_{3}-0.06 \mathrm{BaTiO}_{3}$ solid solutions. J. Alloy. Compd. 2016, 663, 249-255. [CrossRef]

29. Peng, B.L.; Fan, H.Q.; Zhang, Q. A Giant Electrocaloric Effect in Nanoscale Antiferroelectric and Ferroelectric Phases Coexisting in a Relaxor $\mathrm{Pb}_{0.8} \mathrm{Ba}_{0.2} \mathrm{ZrO}_{3}$ Thin Film at Room Temperature. Adv. Funct. Mater. 2013, 23, 2987-2992. [CrossRef]

30. Wu, M.; Song, D.; Vats, G.; Ning, S.; Guo, M.; Zhang, D.; Xue, D.; Pennycook, S.J.; Lou, X. Defect-controlled electrocaloric effect in $\mathrm{PbZrO}_{3}$ thin films. J. Mater. Chem. C 2018, 6, 10332-10340. [CrossRef]

31. Peng, B.; Zhang, Q.; Lyu, Y.; Liu, L.; Lou, X.; Shaw, C.; Huang, H.; Wang, Z. Thermal strain induced large electrocaloric effect of relaxor thin film on $\mathrm{LaNiO}_{3} / \mathrm{Pt}$ composite electrode with the coexistence of nanoscale antiferroelectric and ferroelectric phases in a broad temperature range. Nano Energy 2018, 47, 285-293. [CrossRef]

32. Xue, F.; Liang, L.; Gu, Y.; Takeuchi, I.; Kalinin, S.V.; Chen, L.Q. Composition- and pressure-induced ferroelectric to antiferroelectric phase transitions in $\mathrm{Sm}$-doped $\mathrm{BiFeO}_{3}$ system. Appl. Phys. Lett. 2015, 106, 012903. [CrossRef]

33. Liao, Z.; Xue, F.; Sun, W.; Song, D.; Zhang, Q.; Li, J.-F.; Chen, L.-Q.; Zhu, J. Reversible phase transition induced large piezoelectric response in $\mathrm{Sm}$-doped $\mathrm{BiFeO}_{3}$ with a composition near the morphotropic phase boundary. Phys. Rev. B 2017, 95, 214101. [CrossRef]

34. Cheng, C.J.; Kan, D.; Lim, S.H.; McKenzie, W.R.; Munroe, P.R.; Salamanca-Riba, L.G.; Withers, R.L.; Takeuchi, I.; Nagarajan, V. Structural transitions and complex domain structures across a ferroelectric-to-antiferroelectric phase boundary in epitaxial Sm-doped $\mathrm{BiFeO}_{3}$ thin films. Phys. Rev. B 2009, 80, 014109. [CrossRef]

35. Marzouki, A.; Harzali, H.; Loyau, V.; Gemeiner, P.; Zehani, K.; Dkhil, B.; Bessais, L.; Megriche, A. Large magnetoelectric response and its origin in bulk $\mathrm{Co}$-doped $\mathrm{BiFeO}_{3}$ synthesized by a stirred hydrothermal process. Acta Mater. 2018, 145, 316-321. [CrossRef]

36. Dai, H.; Chen, Z.; Li, T.; Li, Y. Microstructure and properties of Sm-substituted $\mathrm{BiFeO}_{3}$ ceramics. J. Rare Earths 2012, 30, 1123-1128. [CrossRef]

37. Kittel, C. Theory of Antiferroelectric Crystals. Phys. Rev. 1951, 82, 729-732. [CrossRef]

38. Okada, K. Phenomenological Theory of Antiferroelectric Transition I. Second-Order Transition. J. Phys. Soc. Jpn. 1969, 27, 420-428. [CrossRef]

39. Cross, L.E. Antiferroelectric-Ferroelectric Switching in a Simple "Kittel" Antiferroelectric. J. Phys. Soc. Jpn. 1967, 23, 77-82. [CrossRef]

40. Rabe, K.M. Functional Metal Oxides: New Science and Novel Applications; Wiley-VCH Verlag GmbH \& Co. KGaA: Weinheim, Germany, 2013; p. 221.

41. Lines, M.E.; Glass, A.M. Principles and Applications of Ferroelectrics and Related Materials; Clarendon Press: Oxford, UK, 1977.

42. Bai, Y.; Zheng, G.P.; Ding, K.; Qiao, L.J.; Shi, S.Q.; Guo, D. The giant electrocaloric effect and high effective cooling power near room temperature for $\mathrm{BaTiO}_{3}$ thick film. J. Appl. Phys. 2011, 110, 094103.

(C) 2019 by the authors. Licensee MDPI, Basel, Switzerland. This article is an open access article distributed under the terms and conditions of the Creative Commons Attribution (CC BY) license (http://creativecommons.org/licenses/by/4.0/). 